\title{
CLASSIFICATION OF MATURITY LEVEL OF THE MANGOSTEEN USING THE CONVOLUTIONAL NEURAL NETWORK (CNN) METHOD
}

\author{
Oka Sudana $^{1}$, I Putu Agung Bayupati ${ }^{2}$ and Dewa Gede Yudiana ${ }^{3}$ \\ ${ }^{1,2,3}$ Department of Information Technology, \\ Udayana University, Indonesia \\ 19agungokas@unud.ac.id, ${ }^{2}$ bayuhelix@yahoo.com, ${ }^{3}$ yudiana470@ gmail.com
}

\begin{abstract}
Mangosteen (Garcinia Mangostana L.) is a plant that grows in tropical area and originally from Indonesia which becomes the prime commodity of the national trade and has a very big export potential. Mangosteen is a climacteric food so it can be ripen in its storage period. Exported mangosteen needs to pass through the output process, the output process still uses the manual mode . the identification process that uses a person's eyes visually is still having some limits. The process needs more capacity to sort the fruit. With the developed technology nowadays the process itself can be done digitally. This research applied the Deep Learning with Convolution Neural Network (CNN) method which give the $97.1 \%$ accuration result.
\end{abstract}

Keywords - Convolution Neural Network (CNN), Deep learning, Mangosteen, Maturity Level

\section{INTRODUCTION}

Mangosteen (Garcinia Mangostana L.) is a plant that grows in tropical area and originally from Indonesia which becomes the prime commodity of the national trade and has a very big export potential [1]. The opportunities and potential of developing the mangosteen in Indonesia is quite bright at fulfilling the domestic consumsion and the export. The countries such as China, Taiwan, Hong Kong, Middle East (Saudi Arabia, United Arab Emirates, Kuwait, Bahrain, and Qatar), other Asian regions, and also Europe (Netherlands, France, Germany, Italy, and Spain) become the main destination of the mangosteen in 2008. Mangosteen is a climactric food so it can be ripen in its storage period. The climactric peak is after 10 days in the room temperature storage. The harvest is usually at 104 days counted from its blooming flowers. At that time the skin color is green with a bit of light purple at the surface of the skin. Six days after the harvest the skin color becomes dark purple. The harvested dark red colored fruits (114 days) cause the shorter storage capacity and cannot fulfill the exported quality qualifications [2].

The level of maturity of the mangosteen can be classified into the external quality component, which is the color and the texture of the fruit skin. The color is considered as the basic physical property of the agriculture product and food, which correlated with the chemical characteristic and the product quality senses indicator. The color even has a main role in assessing the food industry external quality. The texture will differentiate the physical characteristics of the surface image. Entropy, contrast, energy, and homogenity are the components to measure the texture of the image [3].

The digital image processing method also used in Deep Learning classification method [4]. Deep Learning is a recent science method in Machine Learning field [5]. Deep

Received: August 16, 2019

Reviewed: January 15, 2020

Accepted: February 11, 2020

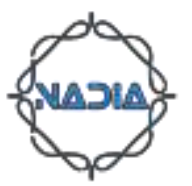


Learning has a very good capability in the Computer Vision. One of them is at the image object classification case. With implementing one of the Machine Learning methods the can be used to classify the image of an object which is Convolution Neural Network (CNN) [6]. There are two steps in the CNN method, Backpropagation and Feedforward [7]. The wrapping and cropping process are done before the classification [8] To focus on the object that will be classified, the Deep Learning method classified the image into two steps, which are training and testing sessions. The training session studies on the extraction feature of every image so it can be differentiated with one another. At the testing session, the image can be analyzed according to the training result. So that the Deep Learning approach is needed to analyze the image from the mangosteen surface and classified the level of the maturity with high accuration [9].

\section{RELATED WORKS}

Similar research is made by the study of the surface defect detection of Mangosteen using Deep Learning method with multilayer convolution. This study used the Deep Learning method to classify the defected mangosteen or not with very high accuracy. This method reaches the maximum value with 4 layers and an Epoch value of 30 parameters. This study resulted in testing for skin detection with 98\% accuracy [10].

This research on detection of citrus maturity condition based on color resemblance to Android based RGB color space explaining that RGB color space (red, green, blue) based on the result of color frequency acquisition by electronic sensors. The output form of this sensor is an analog signal, which the amplitude intensity is digitized and encoded in 8bit for each color. From these three basic colors can form 224 or 16,777,216 other colors. RGB is an additive color space which means all colors are started from black and formed by adding the base colors R, G and B. Each color appears to be a combination of three components of R, G and B [11].

Other related research is the classification of image using the Convolutional Neural Network (CNN) on Caltech. This research performs image classification using Deep Learning methods by utilizing the Convolutional Neural Network algorithm. The trial on this research was to use a total of 390 images on Caltech-101 with 8 categories or classes used. The object image classification with different confusion levels on the Caltech 101 database resulted in an average accuracy value.

This research on the classification of papaya using Artificial Neural Networks method. In this research used the division into three quality classes: Super, A, and B class by producing papaya quality with the best accuracy of $87 \%$ [12].

The following research is a banana maturity detection based on the color features of banana skin image. The method used in this research was the method of transformation of HIS color space. The result of 20 samples of fruits which 10 pieces of raw Ambon Banana and 10 of ripe Ambon Banana with a calculated average maximum value and minimum $\mathrm{H}$ and $\mathrm{S}$ obtained a suitable accuracy of $85 \%$ [13].

The research is about palm biometrics with the method K-Means Clustering and localized arc pattern. The level of accuracy in this research reaches $94 \%$, the clustering process with the use of K-Means algorithm results in a smaller level of accuracy of $92 \%$ of the normalised combination method with scaling and multiplier coefficient $(\alpha=0.6$ and $\beta=0.4)[14]$.

The following research on the introduction of the carp quality with the methods of Wavelet, PCA, Histogram HSV and K-NN. The classification result with K-NN resulted in a total average of its introduction accuracy of $97.8 \%$ using a wavelet extraction method with PCA. The classification result with K-NN resulted in a total average of its introduction accuracy of $98.8 \%$ using the method of extraction of wavelet without PCA [15]. 
Research on identifying the introduction of the medicinal plant using the Localized Arc Pattern feature by using the leaf shape pattern feature. This research recognized $77 \%$ of the total leaves with a False Accepted Ratio (FAR) of $4.5 \%$ and a False Rejection Ratio (FRR) of $18.5 \%$. These results are influenced by shiny leaf surfaces and small leaf shapes [16].

The following research on Hyperspectral image classification with Deep Convolutional Neural Networks. Results are based on multiple Hyperspectral image datasets indicate that the methods used could achieve better classification performance than some traditional methods, such as Vector Machines support and Conventional Deep Learning based methods [17].

The research was about [18] introduction of plant diseases based on the Deep Neural Networks-based leaf image classification. All the important steps required to apply this recognition model, ranging from collecting images to creating databases, those are judged by agricultural experts. The results of experiments on the developed models achieved precision between $91 \%$ and $98 \%$, for the separate class test, averaging $96.3 \%$.

Research [19] related to the introduction of fruit using the Multiple Features and Artificial Neural Network. The method used is the introduction of the fruit that extends the analysis-based features, including textures, colors, and shapes. This system has achieved accuracy of more than $90 \%$ using the successful implementation of the algorithm used.

This research related to the introduction [20] The face is the biometric technology with the Eigenface method using test images and exercise drawings taken directly with the camera on an Android device with a face shooting distance of $60 \mathrm{~cm}$. The results of the test showed that the system resulted in a 94.48\% accuracy with FMR $=2.52 \%$ and FNMR $=3 \%$.

This research is about [21] the detection of disease in corn with a 3,854 image types of diseases in corn plants datasets, consisting of three classifications of corn disease namely Common Rust, Gray Leaf Spot, and Northern Leaf Blight. By producing a 99\% accuracy in detecting the diseases of the corn plant.

The following research [22] on the introduction of Javanese writing uses CNN compared with the performance of the Multilayer Perceptron (MLP) model [23] from the classification accuracy and training time. Test results showed the accuracy of CNN's models was higher than the accuracy of MLP models, although CNN needs longer training time compared to MLP.

\section{PROPOSED METHOD}

This section provides a general view of the proposed algorithm for the identification of mangosteen maturity. The proposed system structure for the classification of Mangosteen maturity is shown in Figure 1. 


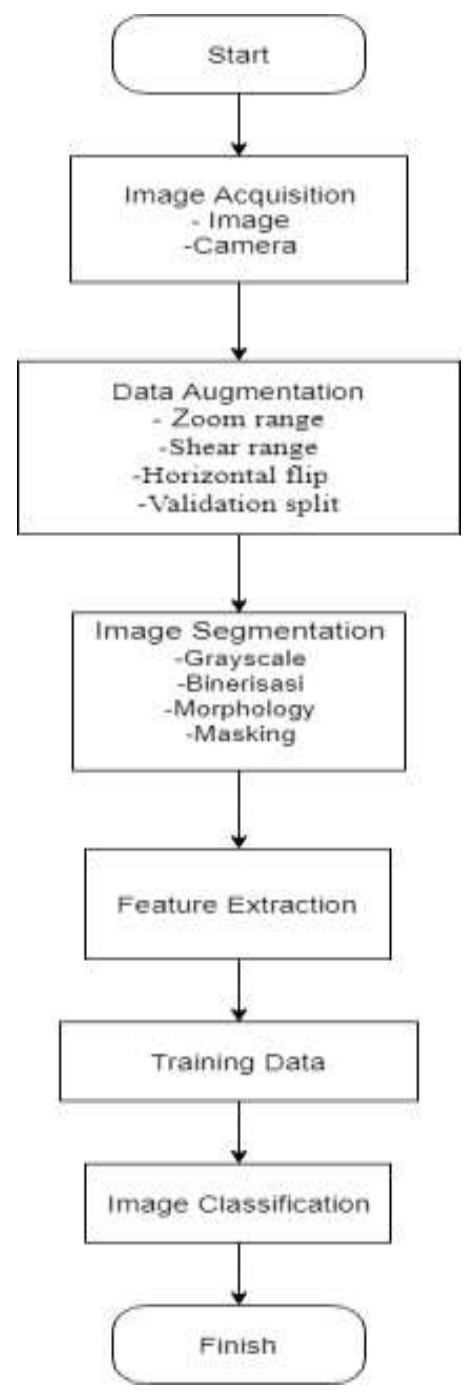

Fig. 1 The Proposed Method Flowchart

\subsection{IMAGE ACQUISITION}

The stage of image acquisition is the initial process of the stage recognition function, including image retrieval process, image cropping. and normalization of the image that can be used in later stages. The image retrieval process can be done through the camera and Internet that has been taken from the tree. The acquisition of Mangosteen has been classified into quality classes, which are grade 0, Grade 1, Grade 2, Grade 3, Grade 4, Grade 5, and Grade 6. The image data taken is 742 with the following details: 140 training data with 79 Mangosteen images in Grade 0,89 Mangosteen pictures in Grade 1, 87 pictures of Mangosteen in Grade 2, 87 pictures of Mangosteen in Grade 3, 102 pictures of Mangosteen in Grade 4, 100 mangosteen pictures in Class 5, 110 the picture of Mangosteen in grade 6 and tested data is from 88 Mangosteen images data. The resulting sample of the Mangosteen image acquisition is shown in Figure 2 [24]. 


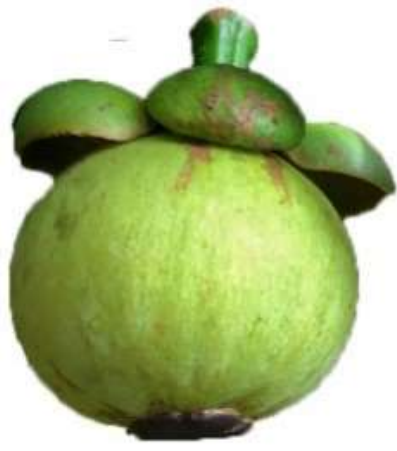

(a)

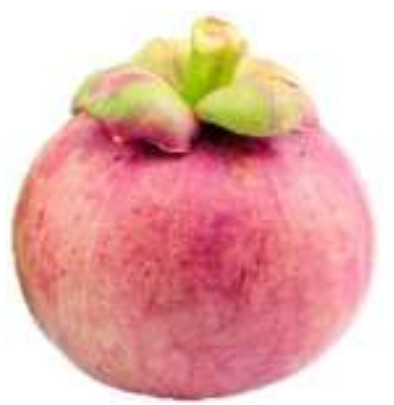

(d)

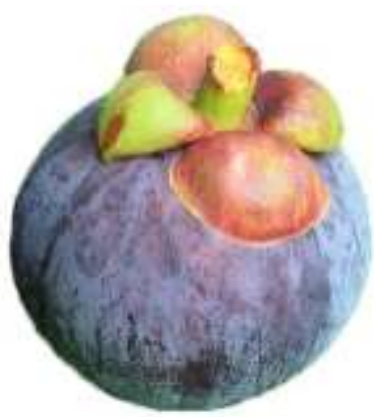

(g)

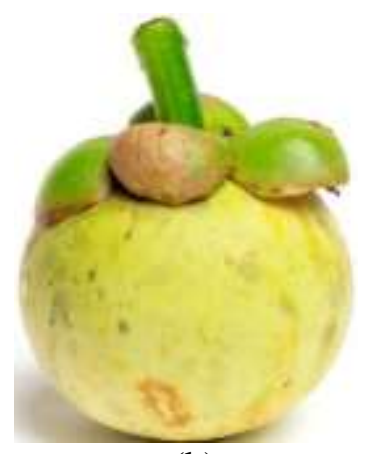

(b)

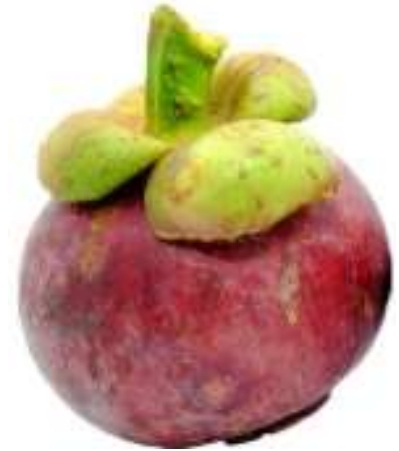

(e)

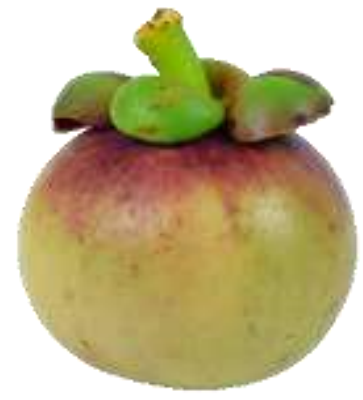

(c)

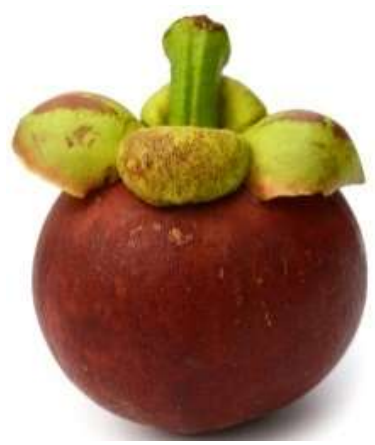

(f)

Fig. 2 Mangosteen Image; (a) Grade 0, (b) Grade 1, (c) Grade 2, (d) Grade 3, (e) Grade 4, (f) Grade 5, and (g) Grade 6

\subsection{SEGMENTATION PROCESS}

Segmentation is the process of splitting one object with another in an image into objects based on a specific characteristic. The segmentation process stops when the searched object has been found. Based on its understanding, segmentation has the purpose of discovering the specific characteristics that the image has. Therefore, segmentation is needed in the process of the pattern recognition. The better the segmentation quality, the better the quality of the pattern recognition. Segmentation process for classification of the maturity level of mangosteen with six processes ranging from the original image, grayscale, bineryzation, morphology, and masking and resulted segmented image. The segmentation process is shown in Figure 3. 


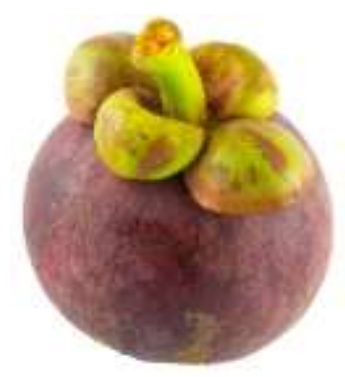

(a)

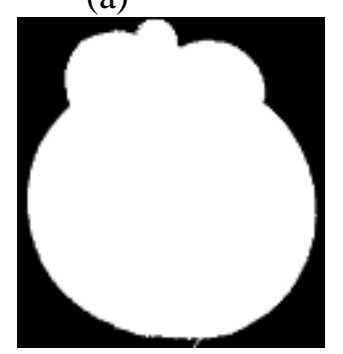

(d)

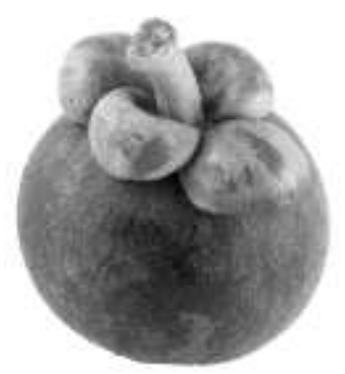

(b)

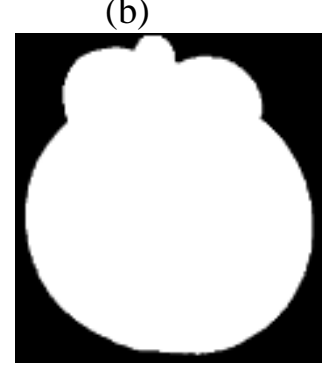

(e)

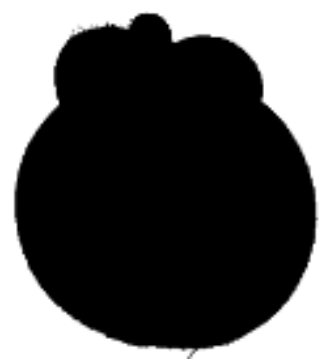

(c)

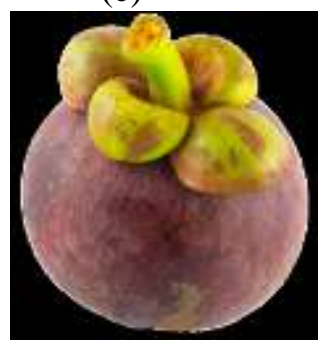

(f)

Fig. 3 Segmentation Process; (a) Initial image, (b) Grayscale, (c) Binary Otsu Mode, (d) Morphology, (e) Masking, and (f) Segmentation Results

\subsection{DATA PREPARATION}

Data Preparation or can also be called as pre-processing data is a process that is done to make raw data into quality data (good input for mining tools data). This process is a step after the image acquisition process is completed. These stages include the process of zoom range, shear range, horizontal flip and validation split. Zoom range is used to set the top or bottom range to zoom in randomly. The shear range is used to regulate Shear Intensity (a sliding angle in counterclockwise direction in degrees) to shift the image to be in-training. Horizontal flip for sets the image horizontally and the validation split is used to set the validation ratio to a specific value.

\subsection{FEATURE EXTRACTION}

Feature extraction is a process for getting features on the image that has been through pre-processing stage. The extraction process in the Maturity Identification application of Mangosteen with CNN method uses the Feature extraction layer that consists of two parts. Convolutional Layer and Pooling Layer. Convolutional layer consists of neurons that are arranged in such a way that forms a filter with a length and height (pixels). Each shift will perform "Dot" operation between the input and the value of the filter thus generating an output or commonly referred as the activation map or feature map. Meanwhile the pooling layer consists of a filter with a specific size and stride that will shift in the entire feature map area. The purpose of using pooling layer is to reduce the feature map dimensions, thereby accelerating the computation since the have to be updated parameters are getting lesser and overcome the overfitting. Then the next process, if the feature map that resulted from the feature exctraction layer is still in the form of multidimensional array, it must perform the reshape feature map into a vector to be used as an input from the Fully Connected Layer. Fully Connected Layer is MLP, which has several hidden layers, activation function, output layer, and loss function.

\subsection{TRAINING DATA}

The overall training process of the convolution network can be summarized as follows. The first step is to initialize all filters and parameters with random values. Furthermore, the network took the image on the training data as an input to further process of the 
Feedforward Propagation on layers contained in CNN architecture and found the output probability for each class. The output probability is random because the weight is set randomly for the first time. The overall error count is set on the layer output. Once the error is obtained, the backpropagation process will be performed on CNN's architectural layers to calculate the gradient error on all the weights in the network by using the descent gradient algorithm to update all the filter values and the Parameters to minimize error output. The weight value is adjusted proportionally to the effect of that weight against total error. As the same image goes into the network on the next epoch gets the value of the output probability close to the target value, it signifies that the network has learned to classify this image properly by adjusting its weight so that the error output can be reduced. Parameters such as the number of filters, filter size, network architecture are fixed and unchanged during the training process, only the values on the filter matrix and the weight value will be updated. Repeat the Feedforward Propagation and Backpropagation steps with all the image data on the trainer until it reaches the end of the specified Epoch. The process will attempt to guess the value of the output class with the actual class value, and if there is an error it will be repeatedly allowed until the end of the specified Epoch limit during the training preparation.

\subsection{TESTING}

Tests or testing process is the process in which the models acquired during the previous training can be used for the new data classification process. To perform the first testing process, it must select the image to be classified in class. After selecting imagery, the classification process will be done. Unlike the previous training process where the output achieved through processes on CNN's architectural layers will be repeated continuously by fixing the classification results until the specified epoch is completed, only inference process is allowed. The process is only one-way, meaning that the output obtained by the process on CNN's architectural layers only resulted once, in other words, no improvement for the classification results. The Output obtained in the testing results is the result of a classification on the previously selected image.

Testing will be conducted several times, starting from a combination of all parameters, the included parameters are; Learning Rate parameter, Epoch and Valilation Data ratio. The accuracy of the Mangosteen Grade quality classification system is calculated with the following equation [12].

Accuracy $(\%)$ percentage of the mangosteen image that recognized according to its class:

\section{RESULTS AND ANALYSIS}

The test of maturity classification of the mangosteen is done to test the electivity and accuracy of the implementation of the methods used. Image of Mangosteen that was obtained through the Internet and taken from the smartphone camera by removing the background. The trial samples that used were 140 with 20 images of each class. Testing was conducted with various parameters on the appropriate methods. The parameter in question is learning rate, epoch and data validation ratio. The purpose of determining the parameter of this model is to compare which model is the best by the parameter value.

The data of each class from 7 classes tested with 20 test data. The test results are in percentages which are then searched for the average and then input them into the table thus generating an actual class confidence level. Sample table results from test data can be seen in Table I. 
Table I. Classification Test Results with Test Data

\begin{tabular}{|c|c|c|c|c|c|c|c|c|}
\hline & \multicolumn{7}{|c|}{ Actual Class } & $\begin{array}{c}\text { Highest } \\
\text { Level of } \\
\text { Confidence }\end{array}$ \\
\cline { 2 - 9 } & $\mathbf{0}$ & $\mathbf{1}$ & $\mathbf{2}$ & $\mathbf{3}$ & $\mathbf{4}$ & $\mathbf{5}$ & $\mathbf{6}$ & $0 \%$ \\
\hline Grade 0 & $91.8 \%$ & $8.2 \%$ & $0 \%$ & $0 \%$ & $0 \%$ & $0 \%$ & $0 \%$ & $\mathbf{9 1 . 8 \%}$ \\
\hline Grade 1 & $2.84 \%$ & $93.9 \%$ & $3.26 \%$ & $0 \%$ & $0 \%$ & $0 \%$ & $0 \%$ & $\mathbf{9 3 . 9 \%}$ \\
\hline Grade 2 & $1.86 \%$ & $4.09 \%$ & $94.05 \%$ & $0 \%$ & $0 \%$ & $0 \%$ & $0 \%$ & $\mathbf{9 4 . 0 5 \%}$ \\
\hline Grade 3 & $0 \%$ & $0 \%$ & $1.47 \%$ & $95.5 \%$ & $3.03 \%$ & $0 \%$ & $0 \%$ & $\mathbf{9 5 . 5 \%}$ \\
\hline Grade 4 & $0 \%$ & $0 \%$ & $0.58 \%$ & $3.72 \%$ & $95.7 \%$ & $0 \%$ & $0 \%$ & $\mathbf{9 5 . 7 \%}$ \\
\hline Grade 5 & $0 \%$ & $0 \%$ & $0 \%$ & $0 \%$ & $0 \%$ & $95.9 \%$ & $4.1 \%$ & $\mathbf{9 5 . 9 \%}$ \\
\hline Grade 6 & $0 \%$ & $0 \%$ & $0 \%$ & $0 \%$ & $1.34 \%$ & $2.66 \%$ & $96 \%$ & $\mathbf{9 6 \%}$ \\
\hline
\end{tabular}

The best model of CNN will be sought based on the parameters that affect the training and testing process. These parameters are test Learning Rate, Epoch and Valilation Data ratios. The test was conducted to determine which scenario has the best result in the classification process.

Table II. Learning Rate Parameters

\begin{tabular}{|c|c|c|c|}
\hline $\begin{array}{c}\text { Learning } \\
\text { rate }\end{array}$ & $\mathbf{0 . 0 1}$ & $\mathbf{0 . 0 0 1}$ & $\mathbf{0 . 0 0 0 1}$ \\
\hline $\mathbf{0}$ & $68.90 \%$ & $78 \%$ & $92.30 \%$ \\
\hline $\mathbf{1}$ & $70.20 \%$ & $82.80 \%$ & $93.75 \%$ \\
\hline $\mathbf{2}$ & $69.50 \%$ & $81.70 \%$ & $92.35 \%$ \\
\hline $\mathbf{3}$ & $62.75 \%$ & $80.35 \%$ & $92.40 \%$ \\
\hline $\mathbf{4}$ & $64.95 \%$ & $77.80 \%$ & $92.55 \%$ \\
\hline $\mathbf{5}$ & $68.20 \%$ & $78.55 \%$ & $91.75 \%$ \\
\hline $\mathbf{6}$ & $68.55 \%$ & $79.60 \%$ & $92.25 \%$ \\
\hline
\end{tabular}

Testing for the value of the learning rate parameter is performed when the epoch value is 20 with the test value of the learning rate parameter $0.01,0.001$, and 0.0001 . The maximum percentage accuracy is obtained when the learning rate value is greater, which is at a value of 0.0001 and then the accuracy continues to last until the next value. An overview of the learning rate parameters is shown with the graph in Figure 4. 


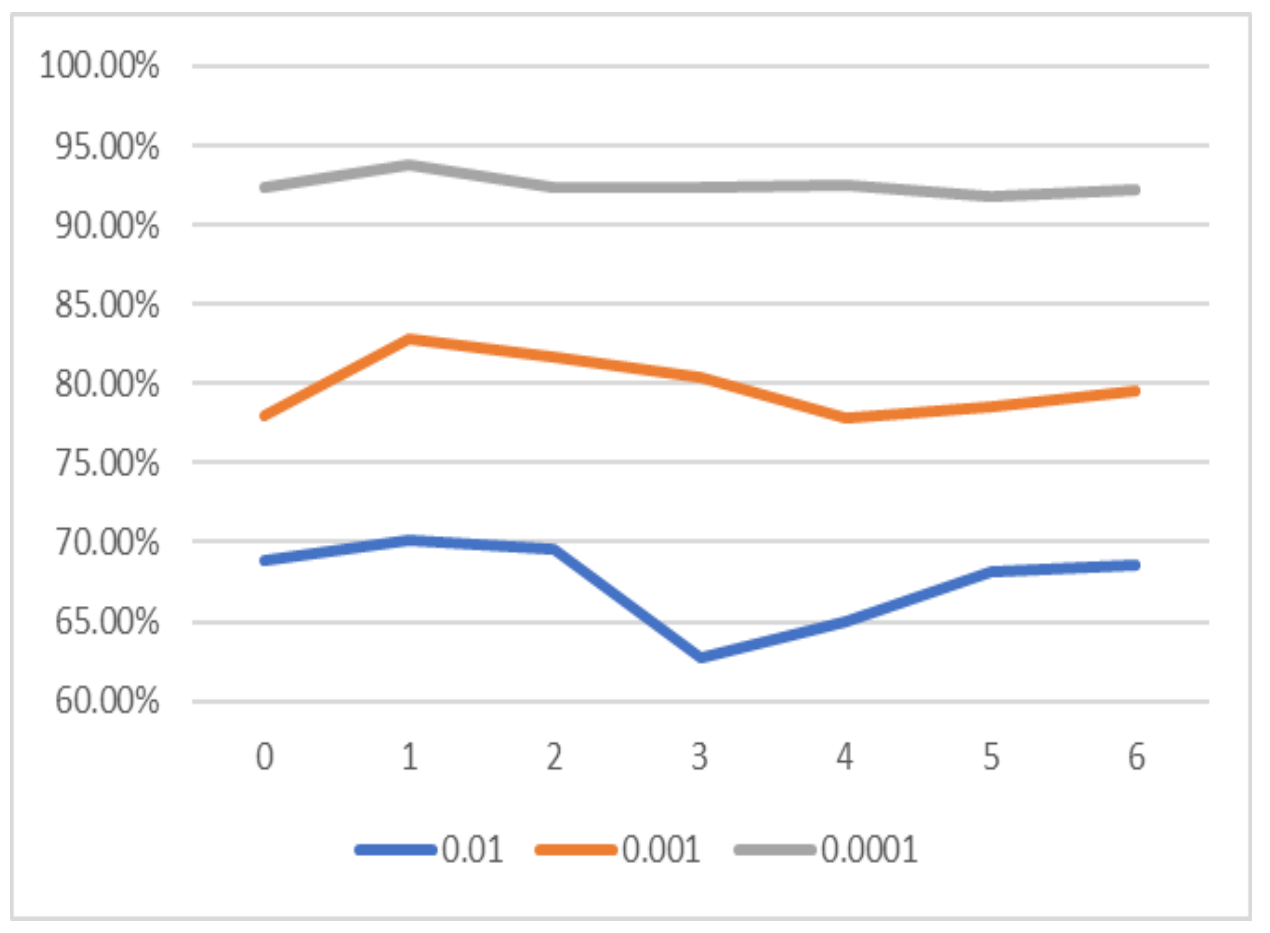

Fig. 4 Graph Effect of Learning Rate Parameters

The graph shown in Figure 4 illustrates that, the effect of the learning rate parameters with a value of 0.001 is lower than the learning rate parameter with a value of 0.01 and a value of 0.0001

Table III. Parameters Epoch

\begin{tabular}{|c|c|c|c|}
\hline Classes & $\mathbf{2 0}$ & $\mathbf{6 0}$ & $\mathbf{8 0}$ \\
\hline $\mathbf{0}$ & $78.20 \%$ & $87.90 \%$ & $91.80 \%$ \\
\hline $\mathbf{1}$ & $78.60 \%$ & $89.20 \%$ & $93.90 \%$ \\
\hline $\mathbf{2}$ & $78.30 \%$ & $87.50 \%$ & $94.05 \%$ \\
\hline $\mathbf{3}$ & $76.95 \%$ & $88.35 \%$ & $95.50 \%$ \\
\hline $\mathbf{4}$ & $75.85 \%$ & $87.95 \%$ & $95.70 \%$ \\
\hline $\mathbf{5}$ & $73.30 \%$ & $88.70 \%$ & $95.90 \%$ \\
\hline $\mathbf{6}$ & $72.90 \%$ & $88.50 \%$ & $96 \%$ \\
\hline
\end{tabular}

Testing for the value of the epoch parameter is performed when the learning rate value is 0.1 with the test values of epoch parameters of 20,60 and 80. The maximum percentage accuracy is obtained when the value of epoch is greater, which is at a value of 80 and then the accuracy continues to persist until the next value. 


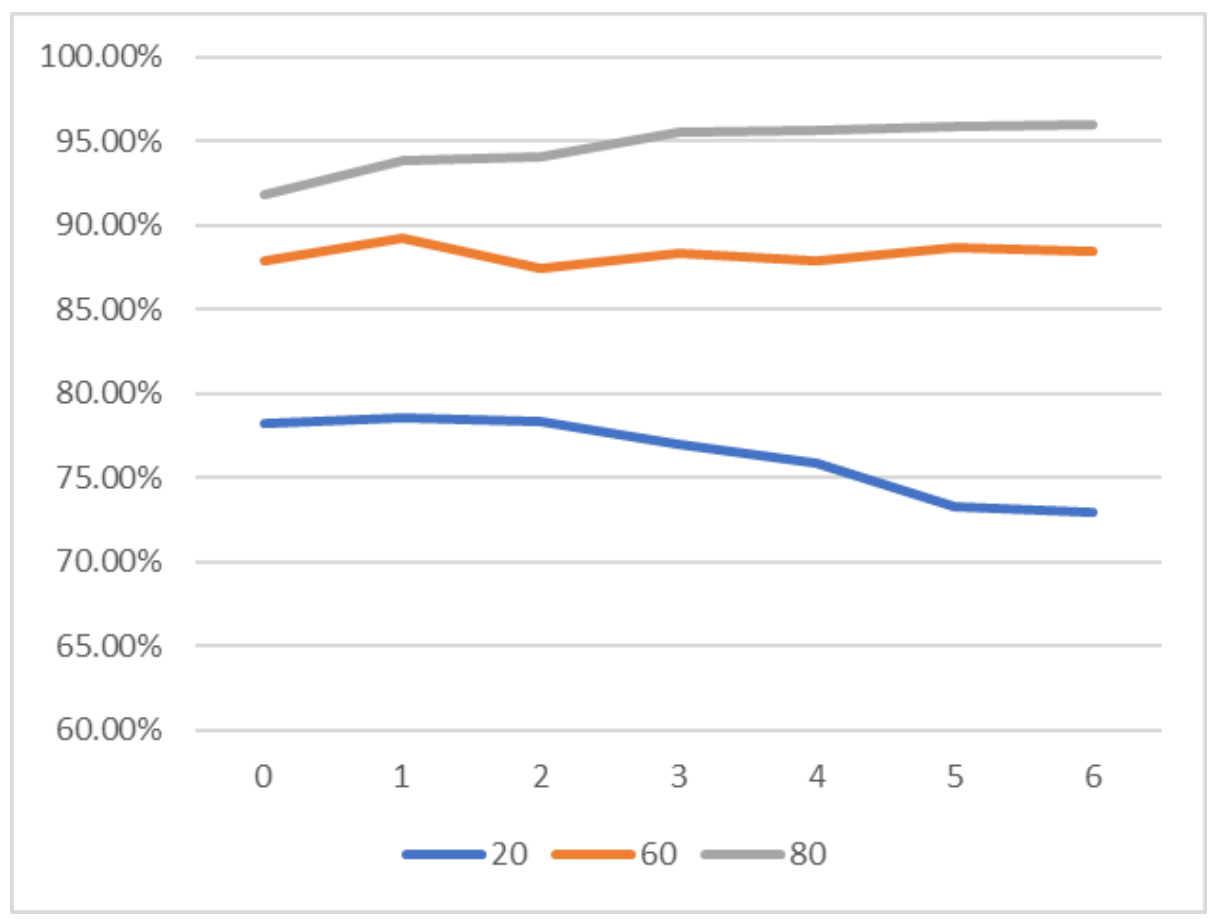

Fig. 5 Graph Effect of Epoch Parameters

The chart shown in Figure 5 illustrates that, the larger the epoch parameter, then the level of accuracy will be higher, but it stops at epoch 80 and then the accuracy continues to persist until the next value.

Table IV. Rasio Validation Parameters

\begin{tabular}{|c|c|c|c|}
\hline $\begin{array}{l}\text { Ratio Val } \\
\text { Classes }\end{array}$ & $10 \%$ & $20 \%$ & $30 \%$ \\
\hline $\mathbf{0}$ & $77.20 \%$ & $89.95 \%$ & $68.70 \%$ \\
\hline 1 & $81.15 \%$ & $92.15 \%$ & $68.85 \%$ \\
\hline 2 & $80.15 \%$ & $90.70 \%$ & $60.25 \%$ \\
\hline 3 & $79.80 \%$ & $92.40 \%$ & $66 \%$ \\
\hline 4 & $75.85 \%$ & $91.80 \%$ & $65.95 \%$ \\
\hline 5 & $77.20 \%$ & $91.85 \%$ & $66.45 \%$ \\
\hline 6 & $80.35 \%$ & $92.50 \%$ & $58.20 \%$ \\
\hline
\end{tabular}

Testing for the validation ratio parameter is done when the epoch value is 20 with the Epoch parameter test value of $10 \%, 20 \%$ and $30 \%$. The maximum accuracy percentage is obtained when the Validation ratio value is at $20 \%$, and then the accuracy continues to decline on the next value. 


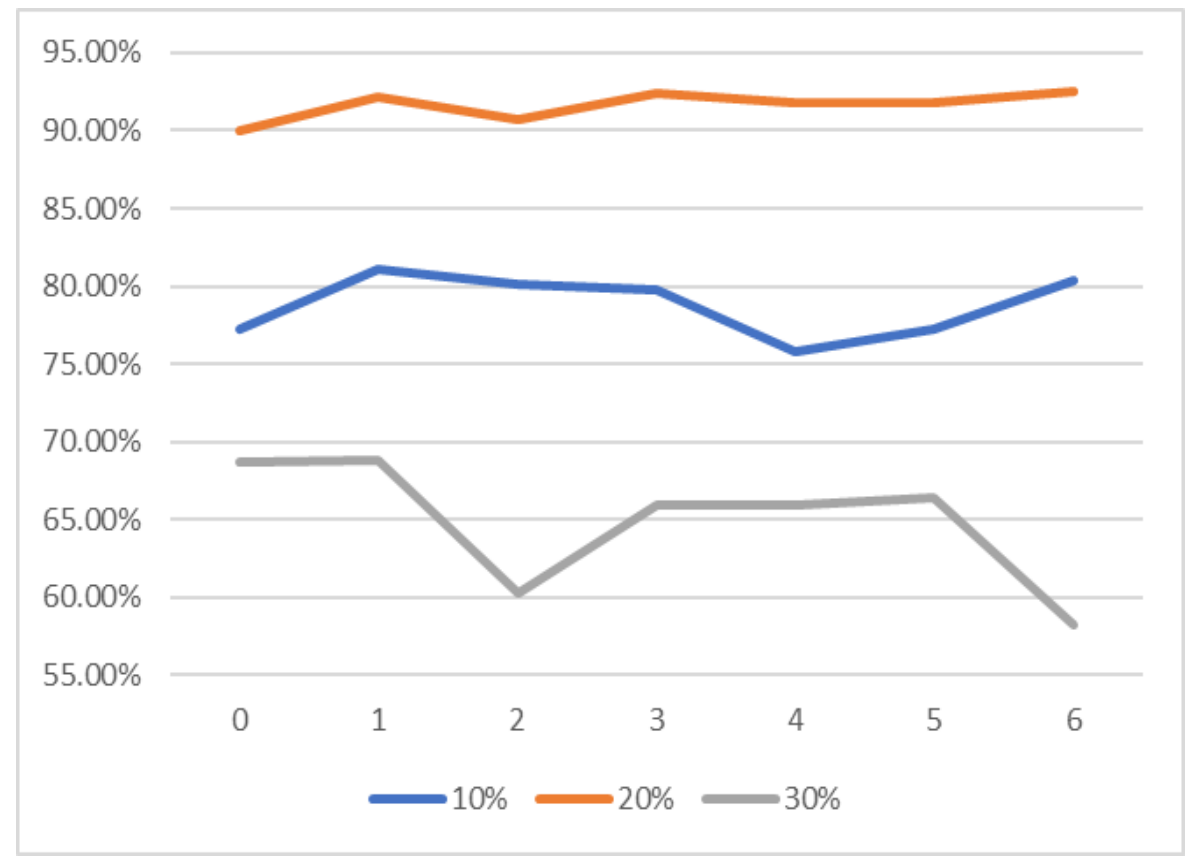

Fig. 6 Graph Effect of Rasio Data Validation Parameters

The chart shown in Figure 6 illustrates that, the larger the validation ratio parameter then the sensitivity, specificity and accuracy levels will be higher but stop at $30 \%$ and then the accuracy continues until The next value.

From the results of Learning Rate parameter, Epoch and Validation ratio resulted in a $97.1 \%$ accuracy rate, this stated that this research was better than previous research using the Artificial Neural Networks methods that generated 94.69\% accuracy [12].

\section{CONCLUSION AND RECOMMENDATION}

This research developed a digital image processing program and the Convolution Neural Network for the maturity classification of the Mangosteen. Based on the research on the classification of the maturity level of mangosteen with digital imaging technology and Convolution Neural Network, the following conclusions are obtained: 1) the process of maturity of Mangosteen is done using Programs that have been successfully designed and manufactured using digital image processing technology for the extraction of Mangosteen features and the Convolution Neural Network as its classification methods; (2) The data set used in this research are amounted to 742 and 140 test Data divided into 7 classes; (3) The testing process uses 3 parameters: Learning Rate, Epoch and data validation ratio, by generating the best accuracy of $94.69 \%$. Further advice can be given for further research: (1) Classification process using the CNN method with more number of datasets; (2) Try using other features either of the shape, texture, and color features.

\section{REFERENCES}

[1] A. Kurniawati, R. Poerwanto, D. Effendi, and H. Cahyana, "Evaluation of Fruit Characters , Xanthones Content, and Antioxidant Properties of Various Qualities of Mangosteens ( Garcinia mangostana L .)," Indonesian Journal of Agronomy, vol. 38, no. 3, pp. 232-237, 2010.

[2] K. P. Badan Penelitian dan Pengembangan Pertanian, "Balai Besar Penelitian dan Pengembangan Pascapanen Pertanian," 2017.

[3] Dian Nursantika. Fajri Rakhmat Umbara, "Pengenalan Citra Buah Manggis Menggunakan Metode Jaringan Syaraf Tiruan Backpropagation,” Infomedia Vol.1 No. 1, vol. 1, no. infomedia, pp. 44-47, 2016.

[4] R. Anitha, S. Jyothi, V. N. Mandhala, D. Bhattacharyya, and T. Kim, "Deep Learning Image Processing 
Technique for Early Detection of Alzheimer' s Disease," International Journal of Advanced Science and Technology, vol. 107, pp. 85-104, 2017.

[5] J. Yun and J. H. Kim, "A Study on Training Data Selection Method for EEG Emotion Analysis using Machine Learning Algorithm," International Journal of Advanced Science and Technology, vol. 119, pp. 79-88, 2018.

[6] J. Seetha and S. S. Raja, "Brain Tumor Classification Using Convolutional Neural Networks," Biomedical \& Pharmacology Journal, vol. 11, no. September, pp. 1457-1461, 2018.

[7] K. Vora and S. Yagnik, "A Survey on Backpropagation Algorithms for Feedforward Neural Networks," International Journal Of Engineering Development And Research, pp. 193-197.

[8] I. A. Habriana Budi Kurniasaria, Susilo, "Penerapan Pengolahan Citra Digital dengan Matlab 7.1 pada Citra Radiografi," Unnes Phisics Journal, vol. 1, no. 2252, pp. 1-4, 2012.

[9] I. W. S. E. Putra, "Klasifikasi Citra Menggunakan Convolutional Neural Network (CNN) Pada Caltech 101,” Jurnal Teknik ITS, vol. 5, no. 1, p. 76, 2016.

[10] L. Marifatul Azizah, S. Fadillah Umayah, and F. Fajar, "Deteksi Kecacatan Permukaan Buah Manggis Menggunakan Metode Deep Learning dengan Konvolusi Multilayer,” Semesta Teknika, vol. 21, no. 2, pp. 230-236, 2018.

[11] H. Prabowo et al., "Deteksi Kondisi Kematangan Buah Jeruk Berdasarkan,” Jurnal Elektronik Sistem Informasi dan Komputer, vol. 3, no. 2, 2017.

[12] F. Wibowo, A. Harjoko, H. Mustafidah, . S., and . A., "The Classification of Papaya using Digital Image Processing and Artificial Neural Networks," International Journal of Advanced Science and Technology, vol. 118, pp. 35-46, 2018.

[13] Indarto and Murinto, "Banana Fruit Detection Based on Banana Skin Image Features Using HSI Color Space Transformation Method," Jurnal Ilmiah Informatika, vol. V, no. November, pp. 15-21, 2017.

[14] D. Rusjayanthi, "Identifikasi Biometrika Telapak Tangan Menggunakan Metode Pola Busur Terlokalisasi, Block Standar Deviasi, dan K-Means Clustering," Lontar Komputer: Jurnal Ilmiah Teknologi Informasi, vol. 4, no. 2, pp. 265-276, 2013.

[15] F. Astutik, "Sistem Pengenalan Kualitas Ikan Gurame dengan Wavelet, PCA, Histogram HSV dan KNN," Lontar Komputer, vol. Vol. 4, no. 2, p. 11, 2013.

[16] N. K. A. Wirdiani and A. A. K. Oka Sudana, "Medicinal plant recognition of leaf shape using Localized Arc Pattern Method," International Journal of Engineering and Technology, vol. 8, no. 4, pp. 1847$1854,2016$.

[17] W. Hu, Y. Huang, L. Wei, F. Zhang, and H. Li, "Deep Convolutional Neural Networks for Hyperspectral Image Classification,” Journal of Sensors, vol. 2015, 2015.

[18] S. Sladojevic, M. Arsenovic, A. Anderla, D. Culibrk, and D. Stefanovic, "Deep Neural Networks Based Recognition of Plant Diseases by Leaf Image Classification," Computational Intelligence and Neuroscience, vol. 2016, 2016.

[19] S. Naskar, "A Fruit Recognition Technique using Multiple Features and Artificial Neural Network," International Journal of Computer Applications, vol. 116, no. 20, pp. 23-28, 2015.

[20] O. K. a Sudana, D. Putra, and A. Arismandika, "Face Recognition System on Android Using Eigenface Method," Journal of Theoretical and Applied Information Technology, vol. 61, no. 1, pp. 128-134, 2014.

[21] A. Hidayat, U. Darusalam, I. Technology, and S. Jakarta, "Detection of Disease on Corn Plants Using Convolutional Neural Network Methods," Journal of a Science and Information, vol. 1, pp. 51-56, 2019.

[22] C. K. Dewa and A. L. Fadhilah, "Convolutional Neural Networks for Handwritten Javanese Character Recognition," Indonesian Journal of Computing and Cybernetics Systems, vol. 12, no. 1, pp. 83-94, 2018.

[23] M. Mahmudul, A. Mia, S. K. Biswas, M. C. Urmi, and A. Siddique, "An Algorithm For Training Multilayer Perceptron ( MLP ) For Image Reconstruction Using Neural Network Without Overfitting .," International Journal Of Scientific \& Technology Research, vol. 4, no. 02, pp. 2-6, 2015. 